\title{
Exploring the urban-rural development differences and influencing factors in the Huang-Huai-Hai Plain of China
}

\author{
CHENG Mingyang ${ }^{1}$, LI Linna ${ }^{1},{ }^{*}$ ZHOU Yang ${ }^{1,2,3}$ \\ 1. Faculty of Geographical Science, Beijing Normal University, Beijing 100875, China; \\ 2. Institute of Geographic Sciences and Natural Resources Research, CAS, Beijing 100101, China; \\ 3. University of Chinese Academy of Sciences, Beijing 100049, China
}

\begin{abstract}
Uneven urban and rural development is one of the main reasons for the decline of the countryside. This imbalance could be measured by the urban-rural difference index (URDI). Existing studies on urban-rural differences have focused on single dimension between urban and rural areas, and lack a systematic multi-dimensional measurement. Based on the construction of an index system and model for measuring urban-rural differences, this study took the Huang-Huai-Hai Plain (HHHP) as the study area, explores the spatial pattern of urban-rural differences in the area, and used geographical weighted regression models to identify the factors affecting urban-rural development differences. Results show that the mean value of URDI in the HHHP was 0.295, and the URDI in its western region was higher than that in the east. The average URDI was relatively high in the western counties along the Beijing-Guangzhou Railway. The low level of urban-rural "population-land-industry" development in the HHHP is an important reason for the small differences between urban and rural areas. Improvements in road transportation infrastructure have led to an increase in the urban-rural development gap. However, the driving force of the road network on urban development is greater than that on rural areas. The role of county economic agglomeration is gaining strength. In the process of rapid economic development, more attention should be paid to the development of the rural economy and the overall revitalization of the countryside. The equivalent allocation of social service facilities is an effective way to solve the problem of urban-rural imbalance. Further analysis demonstrated that terrain factors have relatively little influence on the URDI. This study provides a new perspective and measurement method for understanding the integration of urban and rural development, and provides a useful reference for guiding the urban-rural integration development and the rural revitalization.
\end{abstract}

Keywords: urban-rural difference index (URDI); population-land-industry; urban-rural relationship; rural revitalization; Huang-Huai-Hai Plain (HHHP); China

Received: 2019-09-11 Accepted: 2020-03-22

Foundation: National Key Research and Development Program, No.2017YFC0504701; Major Project of National Social Science Foundation of China, No.15ZDA021; China Postdoctoral Science Foundation, No. 2016M591105

Author: Cheng Mingyang (1988-), PhD Candidate, specialized in land use and urban-rural development.

E-mail: 201731190023@mail.bnu.edu.cn

*Corresponding author: Zhou Yang (1984-), PhD and Associate Professor, specialized in poverty geography and rural revitalization. E-mail: zhouyang@igsnrr.ac.cn 


\section{Introduction}

China has implemented a strict urban and rural household registration system since the founding of the People's Republic of China in 1949. With the implementation of the reform and opening policy in 1978, China's urban and rural household registration system was gradually broken, but the urban-rural dual track system still has a profound impact on China's economy and society (Liu et al., 2010). Since 2003, China has begun to implement a strategy of urban-rural integration, and as a result, rural development has begun to attract attention. However, urban areas still dominate in regional development, while rural areas are increasingly in decline (Liu and $\mathrm{Li}, 2017$ ). The gap between urban and rural areas makes cities fail to establish a good relationship with the countryside, which exacerbates the decline of the countryside (Haas and Westlund, 2018).

The HHHP (also called the North China Plain), which is one of the country's main grain-producing areas, is facing serious problems of rural decline, marginalization of agriculture, weakening of the population, hollowing of villages and environmental pollution. The development model of rural areas supporting cities and agriculture supporting industries has made rural areas unsustainable and aggravated the urban-rural development gap ( $\mathrm{Li}$ and Liu, 2013). The deepening of the urban-rural development gap has in turn made urban-rural segregation severely affecting regional sustainable development. This uncoordinated urban-rural relationship affects the sustainable development of the region and the national food security to some extent (Liu, 2018). Against this background, the differences between urban and rural areas in the main grain-producing areas in China have become an important topic of discussion and an essential part of theoretical studies into urban-rural relationships.

Urban-rural relationships include the fundamental economic and social relationships of an area (Li et al., 2011). In all countries of the world, these relationships have gone through the creation of new cities in the countryside, the separation of urban and rural areas, antagonism between urban and rural areas and integration of urban and rural areas (Zheng and Zheng, 2013). City and the countryside are an organism and should not be separated from each other (Yu and Jiang, 2016). Extensive and in-depth research has been done around urban-rural relations, urban-rural development, and urban-rural integration (Henderson and Wang, 2005; Gren and Andersson, 2018; Yan et al., 2018). At the same time, changes in urban and rural factors are also the focus of attention (Makita et al., 2010; Magnani and Zhu, 2012). Sociology, economics, geography and other disciplines have conducted extensive studies around urban-rural relations and fruitful results have been obtained (Liang et al., 2004; Shi et al., 2004). However, existing studies have mainly focused on the difference of single factor between urban and rural areas, and few studies have systematically considered the gap between multiple factors. In fact, there is a clear gap between urban and rural areas in terms of health, medical services, education and social welfare (Qian and Smyth, 2008; Yi et al., 2008; Fang et al., 2009; Tam, 2015).

An urban-rural regional system is a comprehensive system composed of different subsystems. Urban-rural disparity is an important part of urban-rural relationships. The incoordination between urban and rural areas affects regional sustainable development and exacerbates the decline of rural areas. The question of how to measure the differences between urban and rural areas from a comprehensive perspective remains many challenges. Therefore, the main 
aims of this study are to establish the index system and model of urban-rural development differences, and identify the leading factors affecting the urban-rural development differences. This study provides a new and appropriate concept for understanding urban-rural integrated development and rural revitalization.

\section{Materials and methods}

\subsection{Study area}

The HHHP $\left(32^{\circ}-40^{\circ} \mathrm{N}, 114^{\circ}-121^{\circ} \mathrm{E}\right)$ is one of the largest grain-producing areas in China. The plain spans seven provinces and cities, including Beijing, Tianjin, Hebei, Shandong, Henan, Anhui and Jiangsu, covering an area of about 0.30 million $\mathrm{km}^{2}$ (Figure 1). The average

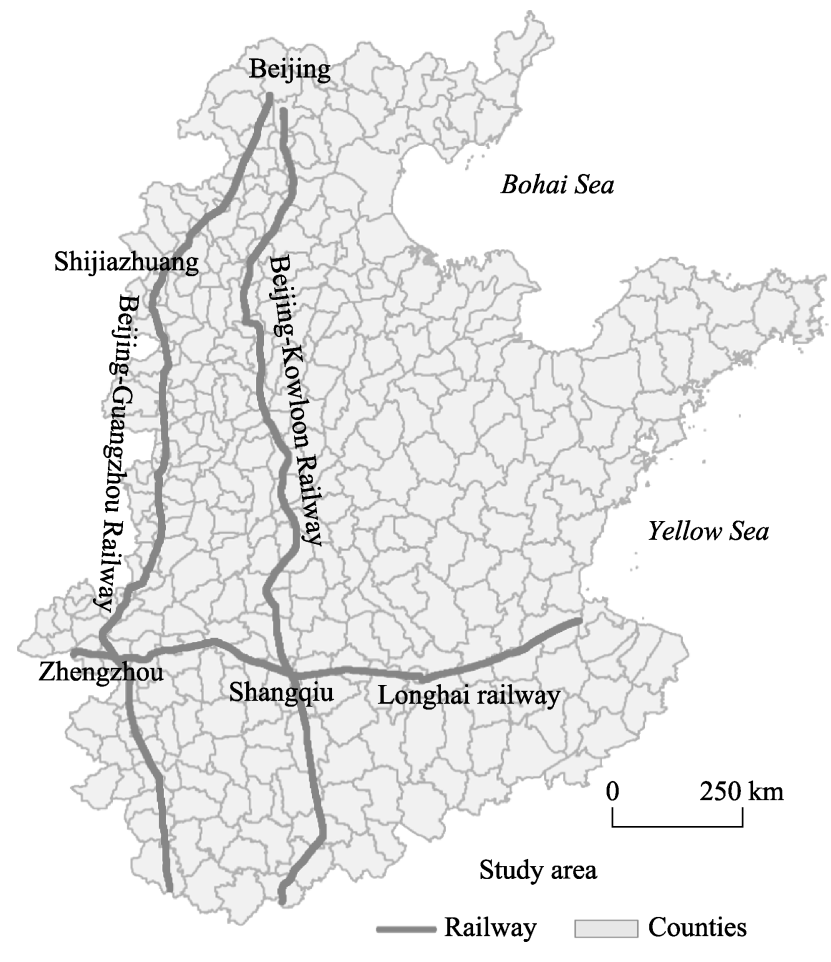

Figure 1 Location of the Huang-Huai-Hai Plain of China annual temperature of the $\mathrm{HHHP}$ is 8 to $15^{\circ} \mathrm{C}$, and the annual rainfall is 500 to $900 \mathrm{~mm}$. In 2015 , the HHHP produced about $24 \%$ of China's grain. The average disposable income of urban residents and rural residents was 25,237 yuan and 12,056 yuan, respectively. The average population density in urban built-up areas and rural settlements was 7400 person $\cdot \mathrm{km}^{-2}$ and 3700 person $\mathrm{km}^{-2}$, respectively. The average secondary and tertiary industrial output value per $\mathrm{km}^{2}$ in urban built-up areas was 1 billion yuan $\mathrm{km}^{-2}$, but the average value of grain output per $\mathrm{km}^{2}$ of cultivated land was just 1.4 million yuan $\mathrm{km}^{-2}$. The average urban per capita output value of secondary and tertiary industries was 94,000 yuan/person, but the average value of rural per capita output value of primary industry was just 9000 yuan/person. Rapid urbanization and industrialization have increased the uneven development of urban and rural areas in the HHHP, which has received widespread attention.

\subsection{Data and methods}

The imbalance between urban and rural development in the HHHP is one of the main driving forces of rural decline. The URDI is a feasible method to measure the development gap between urban and rural areas. Population, land and industry (PLI) are the core elements of the urban-rural system. People is the main body of the system, and their behavior can promote or slow down urban-rural development. Land is the basic element of production and provides a space carrier for development, and industry is the core driving force behind regional economic development. Thus, this study used these three indicators of population, land and industry to analyze the URDI. We constructed an evaluation model for the ur- 
ban-rural difference based on the concept of Euclidean distance (Equation 1). In this study, the values of the URDI range from 0 to 3 . The greater the difference between urban and rural areas is, the greater the URDI is. URDI $=0$ implies no obvious urban-rural development difference, whereas URDI $=3$ indicates the existence of a clear difference.

$$
\mathrm{URDI}_{i}=\sqrt{\left(\mathrm{RP}_{i}-\mathrm{UP}_{i}\right)^{2}+\left(\mathrm{RL}_{i}-\mathrm{UL}_{i}\right)^{2}+\left(\mathrm{RI}_{i}-\mathrm{UI}_{i}\right)^{2}}
$$

where $i$ is the evaluated unit (county); $\mathrm{URDI}_{i}$ is the urban-rural difference index; $\mathrm{RP}_{i}$ is the rural population index; $\mathrm{UP}_{i}$ is the urban population index; $\mathrm{RL}_{i}$ is the rural land index; $\mathrm{UL}_{i}$ is the urban land index; $\mathrm{RI}_{i}$ is the rural industry index $I$; and $\mathrm{UI}_{i}$ is the urban industry index.

The indicators for measuring the URDI include multiple sub-indicators. Urban population (UP) includes the proportion of workers to the total urban population in secondary and tertiary industries and the disposable income of urban residents. Urban land (UL) includes the intensive level of land use in urban built-up areas and the secondary and tertiary industrial output value per $\mathrm{km}^{2}$ in the urban built-up areas. Urban industry (UI) includes the urban per capita output value of secondary and tertiary industries. Rural population (RP) includes the proportion of rural workers to the total rural population and the disposable income of rural residents. Rural land (RL) includes the intensive level of land use in rural settlements and the grain output value per $\mathrm{km}^{2}$ of cultivated land; the grain output value was calculated using the grain price of 2015. Rural industry (RI) includes the rural per capita output value of primary industry. These social and economic data were obtained from the Statistical Yearbook of China's Counties (NBS, 2016) and the individual provincial statistical yearbooks. The data on urban and rural disposable income came from the annual reports of the county governments. In addition, land data came from the Earth System Science Data Sharing Platform of the Chinese Academy of Sciences (CAS) (http://www.gscloud.cn/). All data were standardized to facilitate the elimination of dimensional effects (Equation 2). The UP, RP, UL, RL, UI and RI were obtained by adding sub-indicators with different weights. The indicators were assigned weights using the entropy weight method, whereby the objective weight was determined according to the magnitude of the index variability. Generally, if the information entropy index weight of an index was small in a system, this indicated that the index value could provide much information (Xu et al., 2018). This method eliminates subjective influences (Table 1).

$$
X_{i}^{\prime}=\left(X_{i}-\min X_{i}\right) /\left(\max X_{i}-\min X_{i}\right)
$$

where $X_{i}^{\prime}$ is the value of the normalized index variable; $X_{i}$ is the original value of the index variable; $\min X_{i}$ is the minimum value of the original value of the index variable $X_{i}$; and max $X_{i}$ is the maximum value of the original value of the index variable $X_{i}$.

In general, the level of road network coverage, as well as natural, economic and social factors, are the factors influencing the development of urban and rural areas. The four indicators include different sub-indicators (Table 2). Road network data were obtained from road maps of China (2015) on the Earth System Science Data Sharing Platform, CAS (http://www.gscloud.cn/). These four indicators were also obtained by adding different sub-indicators with different weights, and the weights were obtained by the entropy weight method (Table 2). In order to measure the influence of different factors on URDI, geographical weighted regression (Equation 3), which can be calculated using ArcGIS10.2, was 
applied to analyze the effects. The regression coefficients can be demonstrated using the display function in ArcGIS10.2.

$$
\mathrm{URDI}_{i}=\beta_{0}\left(u_{i}, v_{i}\right)+\sum_{k} \beta_{k}\left(u_{i}, v_{i}\right) x_{i k}+\varepsilon_{i}
$$

where $\beta_{0}\left(u_{i}, v_{i}\right)$ is a constant, $\beta_{k}\left(u_{i}, v_{i}\right)$ is the spatial weight matrix; $x_{i k}$ represents different influencing factors; and $\varepsilon_{i}$ the residual error.

Table 1 Indicators of the urban-rural difference index

\begin{tabular}{|c|c|c|c|}
\hline Destination layer & Criteria layer & Index layer & Weights \\
\hline \multirow{5}{*}{$\begin{array}{l}\text { Urban } \\
\text { development }\end{array}$} & \multirow{2}{*}{ Urban population } & $\begin{array}{l}\text { Proportion of workers to the total urban population in sec- } \\
\text { ondary and tertiary industries }\end{array}$ & 0.50 \\
\hline & & Disposable income of urban residents & 0.50 \\
\hline & \multirow{2}{*}{ Urban land } & $\begin{array}{l}\text { Intensive level of land use in urban built-up areas (per- } \\
\text { son } / \mathrm{km}^{2} \text { ) }\end{array}$ & 0.51 \\
\hline & & $\begin{array}{l}\text { Secondary and tertiary industrial output value per } \mathrm{km}^{2} \text { in } \\
\text { urban built-up areas }\end{array}$ & 0.49 \\
\hline & Urban industry & $\begin{array}{l}\text { Urban per capita output value of secondary and tertiary } \\
\text { industries (yuan per capita) }\end{array}$ & 1.00 \\
\hline \multirow{5}{*}{$\begin{array}{l}\text { Rural } \\
\text { development }\end{array}$} & \multirow{2}{*}{ Rural population } & Proportion of rural workers to the total rural population & 0.50 \\
\hline & & Disposable income of rural residents & 0.50 \\
\hline & \multirow{2}{*}{ Rural land } & Intensive level of land use in rural settlements (person $/ \mathrm{km}^{2}$ ) & 0.51 \\
\hline & & Grain output value per $\mathrm{km}^{2}$ of cultivated land & 0.49 \\
\hline & Rural industry & Output value per capita of rural primary industry & 1.00 \\
\hline
\end{tabular}

Table 2 Indicators of the factors influencing urban-rural development

\begin{tabular}{llc}
\hline \multicolumn{1}{c}{ Factors } & \multicolumn{1}{c}{ Index layer } & Weights \\
\hline \multirow{3}{*}{$\begin{array}{l}\text { Road network } \\
\text { coverage level }\end{array}$} & Highway length per $\mathrm{km}^{2}$ & 0.20 \\
& National road length per $\mathrm{km}^{2}$ & 0.26 \\
& Provincial road length per km ${ }^{2}$ & 0.23 \\
Natural factors & County road length per km ${ }^{2}$ & 0.28 \\
& Railway length per km & 0.13 \\
Economic factors & County average slope & 0.40 \\
& County per capita GDP & 0.30 \\
Social factors & County per capita public finance income & 0.30 \\
& County per capita taxes & 0.31 \\
\hline
\end{tabular}

\section{Results}

\subsection{Spatial pattern of the urban-rural difference index}

The mean value of the URDI in the HHHP was 0.295 , which shows that there is a low level of urban-rural differences. The URDI was relatively high in the western counties of the HHHP along the Beijing-Guangzhou Railway. In this area, the values of most counties' 


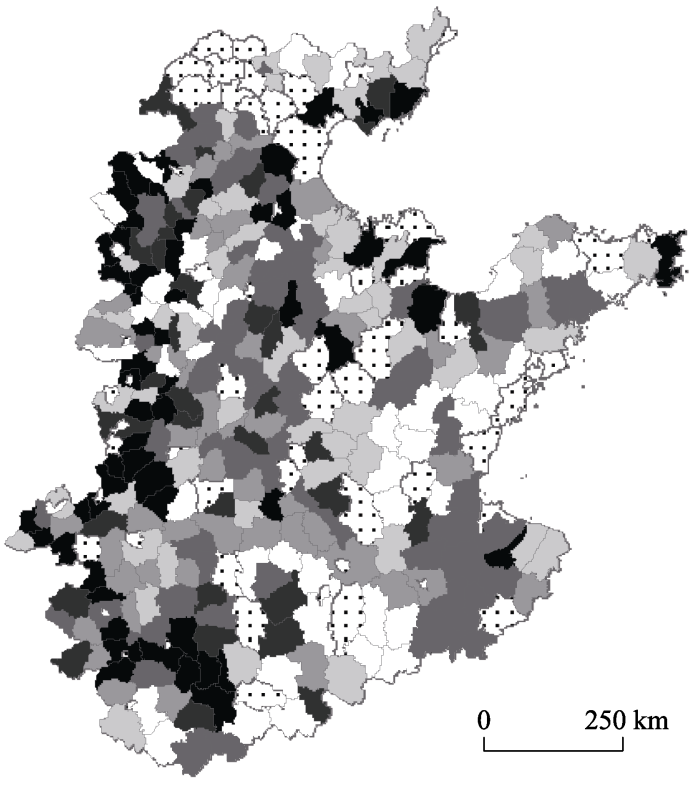

Spatial pattern of urban-rural difference index

\begin{tabular}{l|l|l|l}
$0.03-0.16$ & $0.23-0.28$ & $0.35-0.40 \quad \because: 2:$ No data \\
$0.17-0.22$ & $0.29-0.34$ & $0.41-0.93$
\end{tabular}

Figure 2 Spatial pattern of urban-rural difference index values in the Huang-Huai-Hai Plain in 2015

as a medium development level in the range $(0.3,0.6]$, and the development index is defined as a high level of development in the range $(0.6,1]$ (Table 3$)$.

Table 3 Grading standards for urban-rural development

\begin{tabular}{|c|c|c|c|c|c|c|}
\hline \multicolumn{2}{|c|}{ Urban-rural population } & \multicolumn{2}{|c|}{ Urban-rural land } & \multicolumn{2}{|c|}{ Urban-rural industry } & \multirow{2}{*}{ Development level } \\
\hline $\mathrm{UP}_{i}$ & $\mathrm{RP}_{i}$ & $\mathrm{UL}_{i}$ & $\mathrm{RL}_{i}$ & $\mathrm{UI}_{i}$ & $\mathrm{RI}_{i}$ & \\
\hline$[0,0.3]$ & {$[0,0.3]$} & {$[0,0.3]$} & {$[0,0.3]$} & {$[0,0.3]$} & {$[0,0.3]$} & Low \\
\hline$(0.3,0.6]$ & $(0.3,0.6]$ & $(0.3,0.6]$ & $(0.3,0.6]$ & $(0.3,0.6]$ & $(0.3,0.6]$ & Medium \\
\hline$(0.6,1]$ & $(0.6,1]$ & $(0.6,1]$ & $(0.6,1]$ & $(0.6,1]$ & $(0.6,1]$ & High \\
\hline
\end{tabular}

The UP and RP were all low or medium in most parts of the HHHP, and spatial differentiation was obvious. The proportions of low-level and medium-level urban-rural population were $9.33 \%$ and $49.67 \%$, respectively. In contrast, the proportion of low-level UP and medium-level RP was $28.67 \%$ (Table 4 ). These three types accounted for $87.67 \%$ of the total. This shows that most of the HHHP has a large population and relatively few jobs, which leads to lower income levels in both urban and rural areas. This means that there is a large population base, but there are no corresponding jobs in the local area, which leads to people leaving their hometowns in order to earn higher payment and produces "double drifting in urban and rural areas." Meanwhile, this also indicates that the gap between urban and rural population is small. As rural areas are engaged mainly in agricultural production and other labor-intensive industries, rural areas can bring more jobs than cities. But compared with the secondary and tertiary industries in cities, the rural industries often do not bring too much 
incomes. Urban-rural population development in the western region was relatively low, while that of the eastern region was mainly at the medium level.

Table 4 Proportion of different types of urban-rural population-land-industry in the Huang-Huai-Hai Plain in 2015

\begin{tabular}{|c|c|c|c|}
\hline Development type & $\begin{array}{l}\text { Urban-rural } \\
\text { population }(\%)\end{array}$ & $\begin{array}{l}\text { Urban-rural } \\
\text { land }(\%)\end{array}$ & $\begin{array}{l}\text { Urban-rural } \\
\text { industry (\%) }\end{array}$ \\
\hline Low-level urban-rural development & $9.33(28)$ & $13.33(40)$ & $83.67(251)$ \\
\hline $\begin{array}{l}\text { Low-level urban development and me- } \\
\text { dium-level rural development }\end{array}$ & $28.67(86)$ & $48.00(144)$ & $6.00(18)$ \\
\hline $\begin{array}{l}\text { Low-level urban development and high-level } \\
\text { rural development }\end{array}$ & $0.33(1)$ & $7.33(22)$ & $0.33(1)$ \\
\hline $\begin{array}{l}\text { Medium-level urban development and } \\
\text { low-level rural development }\end{array}$ & $5.00(15)$ & $6.33(19)$ & $7.00(21)$ \\
\hline Medium-level urban-rural development & $49.67(149)$ & $18.00(54)$ & $1.33(4)$ \\
\hline $\begin{array}{l}\text { Medium-level urban development and } \\
\text { high-level rural development }\end{array}$ & $6.33(19)$ & $4.33(13)$ & $0.67(2)$ \\
\hline $\begin{array}{l}\text { High-level urban development and low-level } \\
\text { rural development }\end{array}$ & 0 & $1.00(3)$ & $1.00(3)$ \\
\hline $\begin{array}{l}\text { High-level urban development and me- } \\
\text { dium-level rural development }\end{array}$ & $0.33(1)$ & $1.67(5)$ & 0 \\
\hline High-level urban-rural development & $0.33(1)$ & 0 & 0 \\
\hline
\end{tabular}

Notes: The value in parentheses is the number of counties at the level of development of this type. Cell 9.33 (28) represents the proportions of both urban and rural population at low level is $9.33 \%$, cell 13.33 (40) represents the proportions of both urban and rural land intensification at low level are $13.33 \%$, and so on.

(a) Urban-rural population

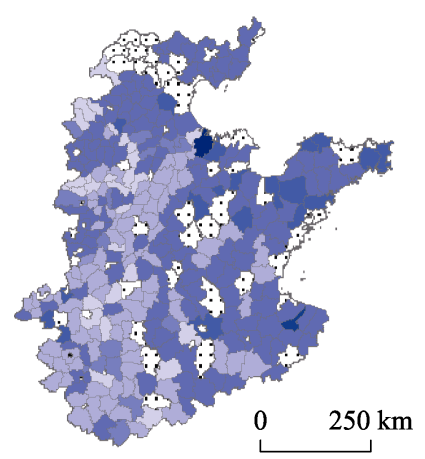

(b) Urban-rural land

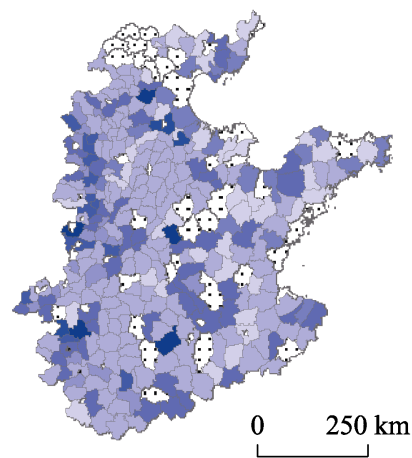

Different types of urban-rural population-land-industry

Low-level of urban-rural development Low-level of urban development and medium-level of rural development Low-level of urban development and high-level of rural development
Medium-level of urban development and low-level of rural development Medium-level of urban-rural development Medium-level of urban development and high-level of rural development (c) Urban-rural industry

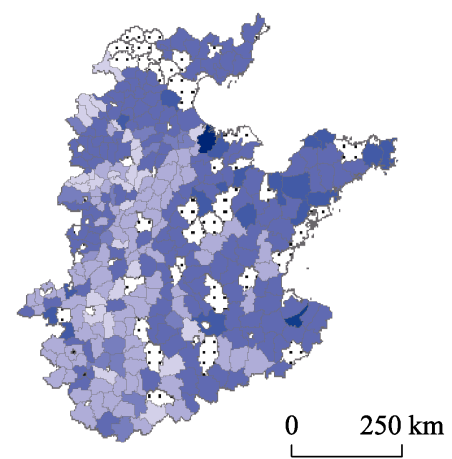

Figure 3 Different types of urban-rural population-land-industry in the Huang-Huai-Hai Plain in 2015

Compared with the spatial pattern of urban-rural population, the spatial differentiation of urban-rural land was not obvious. The medium and low levels of RL and UL were the main types. The proportions of low-level UL and RL, low-level UL and medium-level RL were $13.33 \%$ and $48.00 \%$, respectively. Meanwhile, the proportion of medium-level UL and RL 
was $18.00 \%$ (Table 4 ). These three types accounted for $79.33 \%$ of the total. This shows that the intensity of land use in the HHHP is not high. In other words, per unit area of land can not carry enough population or produce enough output value in most parts of the HHHP. The UL development level was high while RL was relatively low in the western part of the HHHP along the Beijing-Guangzhou Railway. The urban-rural land development of counties in the economic circle around the Bohai Sea was mainly medium-level UL and low-level RL.

Similar to urban-rural population development, the spatial differentiation of urban-rural industry was also obvious. The overall level of urban-rural industrial development was low. The proportion of low-level UI and RI was $83.67 \%$ of the total. Although urban-rural industrial development was low, urban industrial development was greater than its rural counterpart in the HHHP. The differences in the urban-rural industrial development of some counties in the economic circle around the Bohai Sea presented medium-level UI and low-level RI types, as for some counties in Jiangsu Province in the HHHP (Table 4).

\subsection{Factors influencing the urban-rural difference index}

From the development of the four factors including the road network coverage level as well as natural, economic and social factors, we can see that each factor presented different spatial patterns (Figure 4). At the road network coverage level, the overall regional development level was low and that of the highest value was no more than 0.83 . A high-density road network coverage area has formed around Zhengzhou, which is a traffic hub city on the Beijing-Guangzhou Railway, with the Longhai (Lianyungang-Lanzhou) Railway and some other important highways passing through it. Several high-density road network coverage areas have formed around cities on the Beijing-Guangzhou Railway as well, including Baoding, Shijiazhuang, Handan, etc. The coverage level of the road network in the counties surrounding Xuzhou, which is the intersection of the Longhai Railway and the Beijing-Shanghai Railway, was also high. The counties in the economic circle around the Bohai Sea also had high road network coverage levels.

In general, the HHHP has relatively flat terrain, with an average slope below 0.251 in most of this area. In the western part of the plain, the terrain is steeper and its altitude is higher than other parts, as is the area around Shandong. The spatial pattern of economic development in counties was obvious in the HHHP. Economic development in the eastern counties was higher than that in the west. This is also consistent with the decline in China's economic development from the east coast to the central and western parts of the country. The central region showed a typical low-value area of economic development, while the level of development in both eastern and western parts of the area was high. The high-value areas formed an L-shaped spatial pattern for social development. From Baoding to the northern part of Zhengzhou, the extension of the Beijing-Guangzhou Railway has formed a high-development-level axis of social factors, as has the extension of the Longhai Railway from Jiaozuo to Lianyungang. The index of social factors in the economic circle around the Bohai Sea was also high.

In order to explore the factors affecting the URDI, we used geographically weighted regression to analyze the road network coverage level, as well as natural, economic and social factors. By using the Akaike information criterion (AIC) method, the optimal bandwidth was 


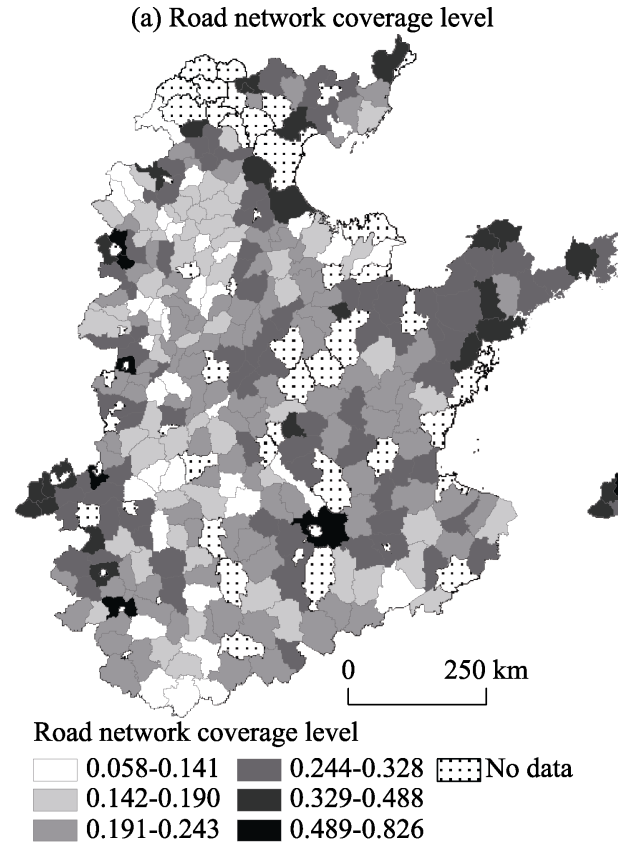

(c) Economic factors

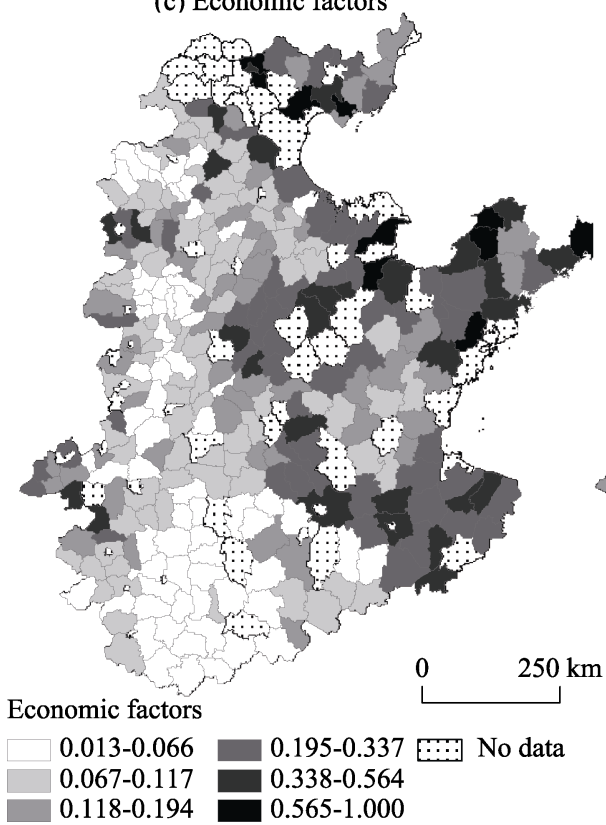

(b) Average slope

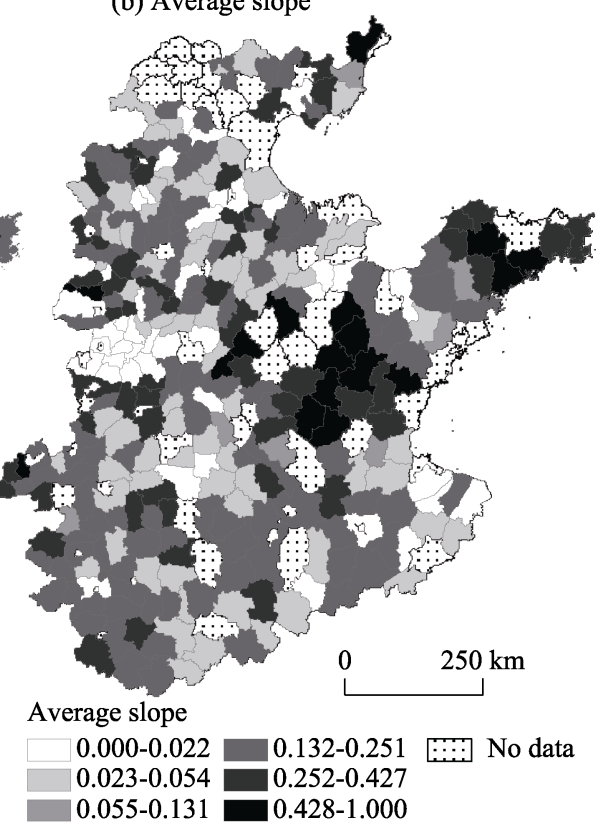

(d) Social factors

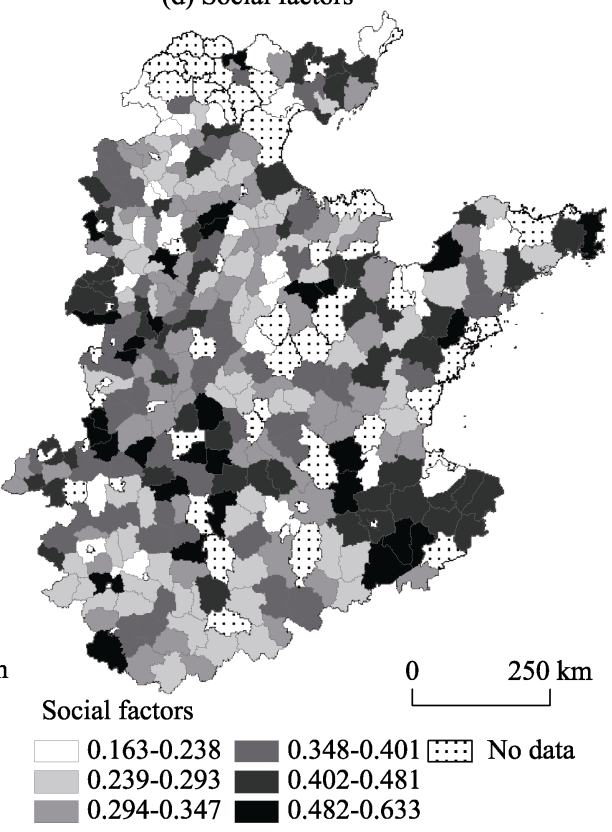

Figure 4 Spatial patterns of road network coverage level, natural, economic and social factors in the Huang-Huai-Hai Plain in 2015

$208151.72 \mathrm{~m}$. The results show that AIC was -378.62 and the $R^{2}$ was 0.29 and the adjusted $R^{2}$ was 0.20 . The regression coefficients of the various factors, which can be used to analyze the intensity of the influencing factors in the different regions, are shown in Figure 5.

In general, the road network coverage level has a positive effect on the regional URDI of western counties and a negative effect on eastern counties, although there are fewer of the latter. That is to say, the greater the density of the road network is, the greater the URDI is in 
(a) Road network coverage level

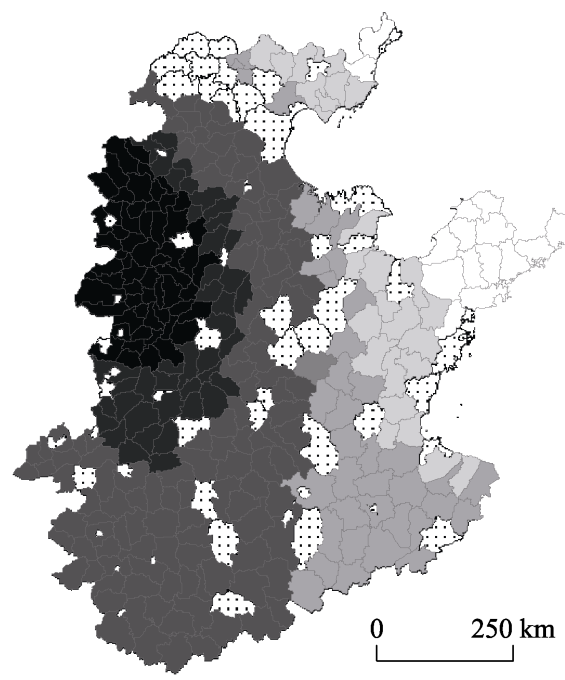

Road network coverage level

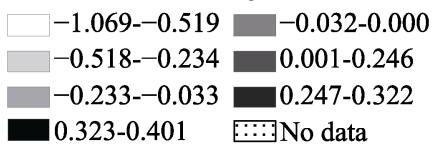

(c) Economic factors

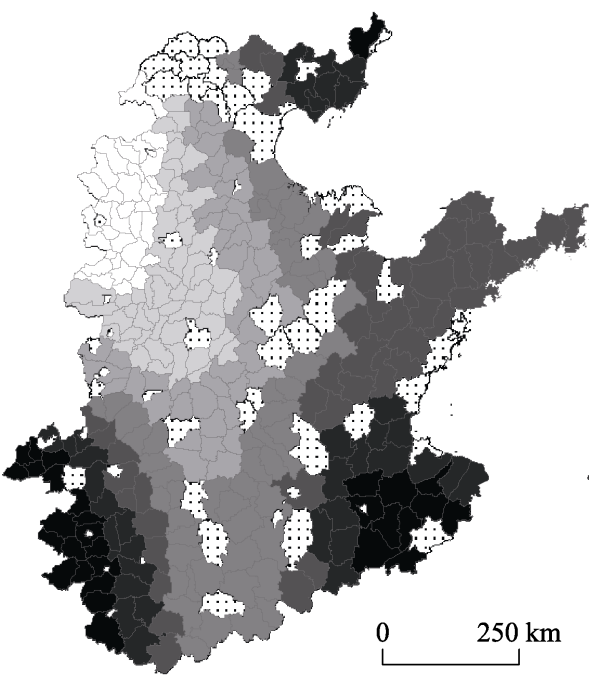

Economic factors

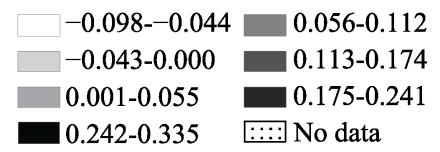

(b) Average slope

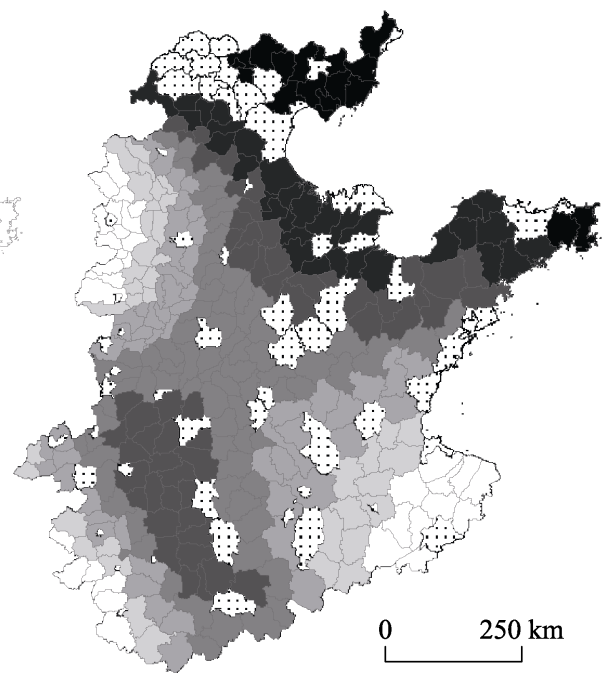

Average slope

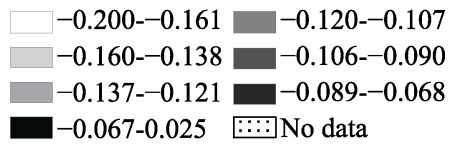

(d) Social factors

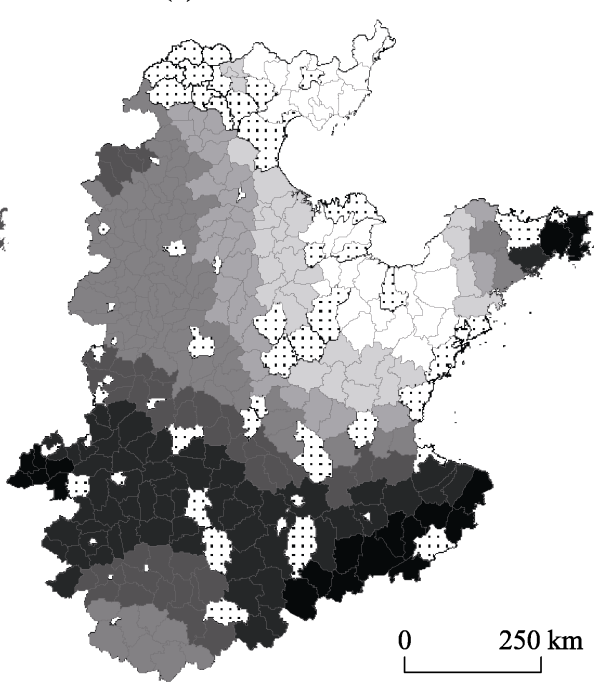

Social factors

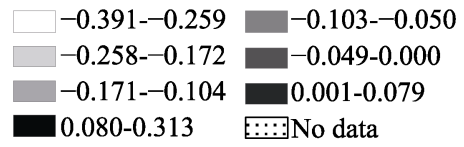

Figure 5 Geographically weighted regression coefficients of the urban-rural difference index in the Huang-Huai-Hai Plain in 2015

the western part of the HHHP. The regression coefficients reflect that the degree of influence declines from west to east. In the western part of the HHHP along the foothills of the Taihang Mountains, the positive influence of traffic factors on the URDI is large over the whole 
area. The absolute values of the negative regression coefficients in the economic circle around the Bohai Sea are also large, and all they are greater than 0.234.

The degree of the average slope has a negative effective on the URDI in the HHHP. This means that the greater the average slope is, the smaller the URDI is. The areas with strong influence are mainly in the western part of Henan and Hebei provinces and the southeast part of the HHHP. The impact of slope on the URDI is small in the economic circle around the Bohai Sea. Overall, the regression coefficients of the average slope are lower than other factors, and their absolute values are less than 0.201.

Economic factors have a positive effect on the URDI, which shows that economic development has exacerbated the difference between urban and rural areas in the HHHP. The influence of economic factors gradually decreases from the south and east to the north and west. The counties with a high positive influence are distributed mainly in the eastern and southwestern parts of the HHHP. Economic factors in some counties of Hebei Province have a negative impact on the URDI, but the absolute values of the regression coefficients are very small. In general, the greater the index of economic factors is, the larger the URDI is.

Although social factors have a negative effect on the URDI in most of the HHHP, they have a positive effect on the URDI in counties that surround cities along the Longhai Railway, such as Zhengzhou, Shangqiu and Xuzhou. However, the regression coefficients of their positive influence are relatively small. This shows that the development of social factors can reduce the URDI, and negative impacts in many counties are obvious (the absolute value of the regression coefficient is large). Therefore, the allocation of social infrastructure can effectively narrow the gap between urban and rural areas.

\section{Discussion}

Previous studies have focused on a single aspect of urban-rural differences, such as income inequality (Yang and Zhou, 1999; Yun, 2011), educational opportunities (Hao et al., 2014) and healthcare (Fang et al., 2009). But few studies have focused on the imbalance between the urban and rural systems. This study can fill this gap. Here, the HHHP was selected as a typical case area, a quantitative model for measuring the urban-rural development difference was constructed, and the spatial pattern of the URDI in the study area in 2015 was investigated, and the leading factors affecting this difference were identified. Our findings can help to reveal the urban-rural relationship in the HHHP.

(1) Urban-rural PLI development is at a low level in the HHHP, which is the main reason for small URDIs in this area. The proportions of urban-rural population, land and industry both at high-level are only $0.33 \%, 0 \%$ and $0 \%$, respectively. Urban-rural development is at a low level in most counties of the HHHP. The development of urban-rural population and industry is relatively low, which reflects that industrial development and job opportunities in the counties are relatively meagre. This is also one of the important reasons for "residential and industrial separation", that is, the low level of industrial development has not brought sufficient jobs to local residents. Therefore, the habitants of the area are forced to leave home to work in other cities for higher payment. In addition, more attention should be paid to avoiding blind urban expansion.

(2) Natural factors have less influence on the URDI than other factors. The negative in- 
fluence of the road network coverage level on the URDI in the economic circle around the Bohai Sea and the positive influence of economic factors are both considerable, while the negative influence of social factors is large, too. This means that this area has achieved better coordinated development between urban and rural areas in the development of society and road facilities. In the process of regional development, economic differences between urban and rural areas should be coordinated. The positive influence of economic and social factors on the URDI in Jiangsu Province is relatively large, whereas the negative influence of road coverage level is obvious. This reflects that the relationship between urban and rural areas has not been coordinated effectively in this region. That means that the overall development of urban and rural areas needs to be strengthened, especially economically and socially. For counties along the Beijing-Guangzhou Railway, the advantages of the transportation infrastructure should continue to be exploited. Meanwhile, attention should also be given to the allocation of social facilities in order to avoid the intensification of these differences.

(3) For most areas, the greater the road network coverage level is, the higher the URDI is. Yang (2016) explored the relationship between urbanization and transportation and proved that the development of counties' urbanization and transportation superiority affected each other significantly. That is to say, the higher the accessibility of transportation is, the more beneficial to a county's urbanization development is. However, the driving force of road network expansion on urban development is greater than that in rural areas. This is the reason why the road network coverage level has a relatively large and positive impact on the URDI. Meanwhile, improvements in transportation can promote the development of rural areas, too. Filani (1993) explored the relationship between transportation and rural development in Nigeria and found that transportation development can improve farmers' productivity and accessibility of the countryside. Although the current transportation system has a positive impact on the URDI in most counties, it still plays an important role in the regional development.

(4) The better the development level of the county economy is, the greater the difference between urban and rural areas is. The town is the growth pole in rural areas around which the economy develops in China. According to growth pole theory, the development of the county economy extending from the urban center to the periphery is a universal phenomenon. In fact, the urban economy is often given priority for development. Under the traditional urban-rural dual track system, rural development is often neglected (Long et al., 2010). So far, urban centers are still the focus of economic development (Chen et al., 2014). Therefore, economic development will lead to an increase in urban-rural differences over time. According to this research, we can see that the development of counties in the HHHP occurred also like this. The agglomeration of urban development is very strong, while the development of the rural economy is relatively backward. So, rural economic development in the HHHP needs to be revitalized urgently, and more attention should be paid to balanced development of urban and rural areas.

(5) The greater the development level of regional social factors is, the smaller the difference between urban and rural areas is. Chen (2015) explored the urban-rural equivalence of China's cities and found that the influence of social factors on urban-rural equivalents is not significant. However, the study showed that the development of social factors can reduce the 
differences between urban and rural areas. In the future of urban-rural development, the rational allocation of social factors is an effective way of narrowing the differences between urban and rural areas. Specifically speaking, welfare, medical and education levels are important factors related to the development of people's livelihoods at the county level, and their development can further narrow the urban-rural gap.

\section{Conclusions}

This study built a quantitative model for measuring the urban-rural development gap from a comprehensive perspective, and analyzed the spatial pattern of the URDI in the HHHP in 2015 based on this, and identified the dominant factors affecting this gap. The results show that this index can reflect the differences in urban-rural development in the HHHP. In general, the URDI in the HHHP was low and its mean value was 0.295. A high value axis has been formed along the Beijing-Guangzhou Railway. The URDI in the western region of the HHHP was higher than that in the eastern area, indicating the existence of an obvious urban-rural development difference in the western region.

The low level of urban-rural PLI development in the HHHP was an important reason for the small differences between urban and rural areas. The proportions of urban-rural population, land and industry both at high-level are only $0.33 \%, 0 \%$ and $0 \%$, respectively. There is a serious separation between rural housing and industry in the whole area. In the future, land use needs to be further developed more intensively. In the HHHP, only the economic circle around the Bohai Sea has achieved a balance between urban and rural areas in both transportation and social development.

The development of the transportation has led to an increase in differences between urban and rural areas. The development of road network has improved the conditions for development of the whole area. However, the rural areas cannot rely on the road network to obtain rapid development because of a lack of rural growth poles, which leads to widening of the URDI. Meanwhile, the role of economic agglomeration in the development of the county is still gaining strength. In the process of economic development, more attention should be paid to the development of the rural economy in the future in order to achieve rural revitalization. The equivalent allocation of social service facilities is an effective way to solve the problem of urban-rural development imbalance. In the HHHP, terrain factors have relatively little influence on the URDI.

\section{References}

Chen C, 2015. Spatio-temporal pattern change and optimized approach of urban-rural equalized development in China [D]. Beijing: University of Chinese Academy of Sciences. (in Chinese)

Chen M X, Huang Y B, Tang Z P et al., 2014. The provincial pattern of the relationship between urbanization and economic development in China. Journal of Geographical Sciences, 24(1): 33-45.

Fang H, Chen J, Rizzo J A, 2009. Explaining urban-rural health disparities in China. Medical Care, 47(12): 1209-1216.

Filani M O, 1993. Transport and rural development in Nigeria. Journal of Transport Geography, 1(4): $248-254$.

Gren $\AA$, Andersson E, 2018. Being efficient and green by rethinking the urban-rural divide: Combining urban expansion and food production by integrating an ecosystem service perspective into urban planning. Sustain- 
able Cities and Society, 40(7): 75-82.

Hao L, Hu A, Lo J, 2014. Two aspects of the rural-urban divide and educational stratification in China: A trajectory analysis. Comparative Education Review, 58(3): 509-536.

Haas T, Westlund H, 2018. In the Post-urban World: Emergent Transformation of Cities and Regions in the Innovative Global Economy. London: Routledge Press.

Henderson J V, Wang H G, 2005. Aspects of the rural-urban transformation of countries. Journal of Economic Geography, 5(1): 23-42.

Li Y H, Liu Y S, 2013. Investigation of the resource \& environment issues in the urban-rural transition in China. Economic Geography, 33(1): 61-65. (in Chinese)

Li Y R, Liu Y S, Long H L, 2011. Study on the pattern and types of rural development in the Huang-Huai-Hai region. Geographical Research, 30(9): 1637-1647. (in Chinese)

Liang X C, Ming X D, Ling Z X, 2004. Evaluation of urban-rural integration course in northeast China. Scientia Geographica Sinica, 24(3): 320-325. (in Chinese)

Liu Y S, 2018. Research on the urban-rural integration and rural revitalization in the new era in China. Acta Geographica Sinica, 73(4): 2-14. (in Chinese)

Liu Y S, Li Y H, 2017. Revitalize the world's countryside. Nature, 548(7667): 275-277.

Liu Y S, Li Y R, Chen Y F et al., 2010. The process and driving forces of rural hollowing in China under rapid urbanization. Journal of Geographical Sciences, 20(6): 876-888.

Long H L, Liu Y S, Li X B et al., 2010. Building new countryside in China: A geographical perspective. Land Use Policy, 27(2): 457-470.

Magnani E, Zhu R, 2012. Gender wage differentials among rural-urban migrants in China. Regional Science \& Urban Economics, 42(5): 779-793.

Makita K, Fèvre E M, Waiswa C et al., 2010. Population-dynamics focussed rapid rural mapping and characterisation of the peri-urban interface of Kampala, Uganda. Land Use Policy, 27(3): 888-897.

National Bureau of Statistics (China), 2016. Statistical Yearbook of China's Counties 2016. Beijing: China Statistics Press. (in Chinese)

Qian X, Smyth R, 2008. Measuring regional inequality of education in China: Widening coast-inland gap or widening rural-urban gap? Journal of International Development, 20(2): 132-144.

Shi Y, Guo F, Nipper J, 2004. A comparative study on integration of urban and rural areas between the developed areas in China and Germany: A case study of Yangtze Delta and the lower reaches of Rhine. Human Geography, 19(2): 25-29. (in Chinese)

Tam T J J, 2015. Divergent urban-rural trends in college attendance: State policy bias and structural exclusion in China. Sociology of Education, 88(2): 160-180.

Xu H S, Ma C, Lian J J et al., 2018. Urban flooding risk assessment based on an integrated k-means cluster algorithm and improved entropy weight method in the region of Haikou, China. Journal of Hydrology, 563(8): 975-986.

Yan J M, Chen H, Xia F Z, 2018. Toward improved land elements for urban-rural integration: A cell concept of an urban-rural mixed community. Habitat International, 77: 110-120.

Yang D T, Zhou H, 1999. Rural-urban disparity and sectoral labour allocation in China. Journal of Development Studies, 35(3): 105-133.

Yang R, 2016. Spatial coupling cooperative analysis of road transport superiority and urbanization at county level in China. Progress in Geography, 35(7): 806-815. (in Chinese)

Yu W, Jiang X, 2016. The third-type settlement: Research of unified urban and rural living organisms and its interaction design. In: Design, User Experience, and Usability: Novel User Experiences. Berlin: Springer International Publishing.

Zheng W Z, Zheng X B, 2013. The space-time evolutional pattern of core town's function to the integration of urban and rural areas: Theory and evidence. Economic Geography, 33(6): 79-83. (in Chinese)

Zhu Y, 2011. Difference of urban-rural residents' income and consumption in Chongqing City from 2000 to 2009. Journal of Anhui Agricultural Sciences, 39(24): 15104-15107. (in Chinese) 